\title{
Impactos dos fatores extrínsecos no envelhecimento precoce: Uma reflexão teórica
}

\author{
Impacts of extrinsic factors on early aging: A theoretical reflection \\ Impactos de los factores extrínsecos em el envejecimiento temprano: Uma reflexióm teórica
}

Recebido: 04/05/2021 | Revisado: 09/05/2021 | Aceito: 11/05/2021 | Publicado: 28/05/2021

\author{
Isabela Nascimento Ferraz \\ ORCID: https://orcid.org/0000-0001-9701-4975 \\ Faculdade Independente do Nordeste, Brasil \\ E-mail: isabelanferraz@gmail.com \\ Luciana Araújo dos Reis \\ ORCID: https://orcid.org/0000-0002-0867-8057 \\ Universidade Estadual do Sudoeste da Bahia, Brasil \\ E-mail: lucianauesb@yahoo.com.br \\ Wagner Couto Assis \\ ORCID: https://orcid.org/0000-0001-7802-2443 \\ Universidade Estadual do Sudoeste da Bahia, Brasil \\ E-mail: wagnerassis2010@hotmail.com \\ Lilian Almeida Nascimento Rabelo \\ ORCID: https://orcid.org/0000-0001-7457-6510 \\ Faculdade de Tecnologia e Ciências, Brasil \\ E-mail: lynascimento@hotmail.com \\ Frank Evilácio de Oliveira Guimarães \\ ORCID: https://orcid.org/0000-0003-4739-3676 \\ Universidade Católica do Salvador, Brasil \\ E-mail: frankevilacio@hotmail.com \\ Isnara Teixeira de Brito \\ ORCID: https://orcid.org/0000-0001-7916-2085 \\ Universidade Estadual do Sudoeste da Bahia, Brasil \\ E-mail: isnara.britto@hotmail.com \\ Luana Araújo dos Reis \\ ORCID: https://orcid.org/0000-0002-9263-083X \\ Faculdade Independente do Nordeste, Brasil \\ E-mail: luareis1@hotmail.com
}

\begin{abstract}
Resumo
Objetivo: Descrever os impactos dos fatores extrínsecos no envelhecimento precoce, a partir de uma reflexão teórica. Metodologia: Trata-se de um ensaio teórico de caráter reflexivo, por meio de uma revisão bibliográfica não sistemática sobre o tema "fatores extrínsecos e envelhecimento precoce", e também através da percepção dos autores acerca da temática. Como estratégia de busca foram definidas bases de dados eletrônicas, bibliotecas virtuais, respectivamente o Science Direct, o Scielo e o Google Acadêmico, utilizando os descritores padronizados pelo Descritores em Ciências da Saúde (Decs): envelhecimento; envelhecimento da pele; radicais livres; tabagismo; senilidade prematura, e seus correspondentes em inglês. O levantamento limitou-se aos artigos publicados em português, inglês e espanhol, publicados no período de 2010 a 2020, disponíveis na íntegra e cujos resultados abrangessem o tema desta pesquisa. Resultados: A análise da literatura foi disposta em dois subtemas: "Envelhecimento Cutâneo" e "Envelhecimento Extrínseco". Considerações Finais: Ao analisar os tópicos abordados é possível verificar quanto os fatores extrínsecos influenciam o envelhecimento precoce e que para a diminuição dessa influência as pessoas devem optar por uma vida mais saudável.
\end{abstract}

Palavras-chave: Envelhecimento; Envelhecimento da pele; Radicais livres; Tabagismo; Senilidade prematura.

\begin{abstract}
Objective: Describe the impacts of extrinsic factors on premature aging, from a theoretical reflection. Methodology: This is a reflective theoretical essay, through a non-systematic bibliographic review on the theme "extrinsic factors and premature aging", and also through the authors perception of the theme. As a search strategy, eletronic databases and virtual libraries were defined, respectively Science Direct, Scielo and Google Scholar, using the descriptors standardized by the Health Sciences Descriptors (Decs): aging; skin aging; free radicals; smoking; premature senility, and their English counterparts. The survey was limited to articles published in Portuguese, English and Spanish, published in the period from 2010 to 2020, available in full and whose results covered the theme of this research. Results: The literature analysis was arranged in two sub-themes: "Cutaneous Aging" and " Extrinsic Aging". Final
\end{abstract}


Considerations: When analyzing the topics covered, it is possible to verify how much extrinsic factors influence premature aging and that to reduce this influence, people should choose a healthier life.

Keywords: Aging; Skin aging; Free radicals; Smoking; Premature senility.

\section{Resumen}

Objetivo: Describir los impactos de los factores extrínsecos sobre el envejecimiento prematuro, a partir de uma reflexión teórica. Metodología: Se trata de um ensayo teórico reflexivo, a través de uma revisión bibliográfica no sistemática sobre el tema "factores extrínsecos y envejecimiento prematuro", y también a través de la percepción de los autores sobre el tema. Como estratégia de búsqueda se definieron bases de datos electrónicas e bibliotecas virtuales, respectivamente Science Direct, Scielo y Google Scholar, utilizando los descriptores estandardizados por los Descriptores de Ciencias de la Salud (Decs): envejecimiento; envejecimiento de la piel; radicales libres; de fumas; senilidade prematura y sus homólogos ingleses. La encuesta se limito a artículos pulicados en português, inglês y español, publicados en el período de 2010 a 2020, disponibles em su totalidade y cuyos resultados cubrieron el tema de esta investigación. Resultados: El análisis de la literatura se organizo en dos subtemas: "Envejecimiento cutâneo" y "Envejecimiento extrínseco". Consideraciones Finales: Al analizar los temas tratados, es posible verificar cuánto influyen los factores extrínsecos en el envejecimiento prematuro y que para reducir esta influencia las personas deben optar por una vida más saludable.

Palabras clave: Envejecimiento; Envejecimiento de la piel; Radicales libres; De fumar; Senilidade prematura.

\section{Introdução}

O envelhecimento é um processo natural de todo ser humano. A Organização Mundial de Saúde (OMS, 2015) menciona a amplitude de oportunidades que vem ajudando no aumento da longevidade, porém os seus impactos dependerão da saúde do idoso. Se as pessoas vivenciam a velhice se cuidando, cuidando da sua saúde e sendo produtivos, serão idosos fortes e independentes.

O ser humano como um todo sempre se preocupou com o envelhecimento, encarando-o de formas diferentes. Alguns relatam que é caracterizada pela diminuição dos dias de vida, outros veem como um período de crescente vulnerabilidade e dependência. Existem ainda os que acham que a velhice é o ápice da vida e veem ela como um momento de sabedoria, bom senso e serenidade (Fechine; Trompieri, 2012).

Segundo a OMS (2005), os idosos em países desenvolvidos são aqueles com idade igual ou superior a 65 anos. Em países em desenvolvimento são aqueles com idade igual ou superior a 60 anos. Em 2007 o envelhecimento foi classificado em dois grupos, idosos entre 60 e 80 anos e idosos com idade superior a 80 anos (OMS, 2005 apud Mendes, 2020). A OMS (2015) defende que não existe um idoso típico que as diversidades ocorrem ao longo do desenvolvimento do indivíduo.

Atualmente a população brasileira vive um dos maiores processos de envelhecimento. O principal motivo é a queda das taxas de fecundidade e o aumento da expectativa de vida. Em 2050, estima-se que os idosos representem aproximadamente 14\% da população brasileira (Barbon; Wieltholter; Flores, 2016).

O envelhecimento é um processo biológico que acomete a todos, mas existem fatores que podem induzir ou retardar esse processo. Com o avanço da idade a pele sofre alterações cutâneas que comprometem e modificam suas funções naturais, que ocorrem pelas alterações morfológicas e fisiológicas no organismo ao longo da vida (Macena; Hermano; Costa, 2018).

O envelhecimento precoce está relacionado com as agressões externas que a pele sofre e o principal deles é a radiação UV, que é o mais importante responsável pelo envelhecimento. A incidência da luz sobre a pele causa um efeito cumulativo, onde só podem ser observadas as agressões com o tempo e não de imediato (Fagnan et al., 2014).

Dentre os fatores que influenciam o envelhecimento estão os fatores extrínsecos, que são determinados por raios ultravioletas, que influenciam a foto envelhecimento, o tabagismo e álcool, que provocam vasoconstrição da pele e diminui a produção de fibroblastos e os radicais livres (RL), que causam danos às células normais e consequentemente aceleram o processo de envelhecimento (Teixeira et al., 2018). 


\section{Metodologia}

Trata-se de um ensaio teórico de caráter reflexivo, da literatura sobre os impactos dos fatores extrínsecos no envelhecimento precoce, por meio de uma revisão bibliográfica não sistemática, com abordagem qualitativa, sobre o tema "fatores extrínsecos e envelhecimento precoce”, e também através da percepção dos autores acerca da temática. De acordo Gil (2017) a pesquisa bibliográfica permite analisar uma temática sob diversos estudos de maneira ampla e concisa.

Já a abordagem qualitativa responde a questões muito particulares. Ela se preocupa, nas ciências sociais, com um nível de realidade que não pode ser quantificado. Ou seja, ela trabalha com o universo de significados, motivos, aspirações, crenças, valores e atitudes, o que corresponde a um espaço mais profundo das relações, dos processos e dos fenômenos que não podem ser reduzidos à operacionalização de variáveis (Minayo, 2001, p. 21-22).

Como estratégia de busca foram definidas bases de dados eletrônicas, bibliotecas virtuais, respectivamente o Science Direct, o Scielo e o Google Acadêmico, utilizando os descritores padronizados pelo Descritores em Ciências da Saúde (Decs): envelhecimento; envelhecimento da pele; radicais livres; tabagismo; senilidade prematura, e seus correspondentes em inglês. $\mathrm{O}$ levantamento limitou-se aos artigos publicados em português, inglês e espanhol, publicados no período de 2010 a 2020 , disponíveis na íntegra e cujos resultados abrangessem o tema desta pesquisa. As impressões e considerações da análise da literatura serão dispostas em dois subtemas "Envelhecimento Cutâneo" e "Envelhecimento Extrínseco". Dessa forma, o ensaio objetiva descrever os impactos dos fatores extrínsecos no envelhecimento precoce, a partir de uma reflexão teórica.

\section{Resultados e Discussão}

\section{Envelhecimento Cutâneo}

A pele é o maior órgão do corpo humano, é um órgão de revestimento e é constituída por três camadas, sendo elas a epiderme, a derme e a hipoderme (Teston et al., 2010; Bento, 2015). É encontrada na pele o colágeno e a elastina, que são responsáveis pela sustentação e sua degradação provoca o aparecimento de rugas e perda de elasticidade, sendo possível perceber o envelhecimento visivelmente na pele (Lima, 2018).

Segundo Carvalho et al. (2016, p. 04),

"o envelhecimento altera todos os tecidos do corpo, na face por exemplo, ocorre o remodelamento do arcabouço ósseo, o crânio torna-se mais fino, ocasionando falta de estrutura de sustentação da face, levando a um excesso de tecido facial; movimentos musculares repetidos, ocasionando rugas dinâmicas que podem evoluir para linhas e sulcos permanentes; perda da gordura facial, acentuando a depressão malar e submalar, perda do contorno da face, acentuando a prega nasolabial, já o envelhecimento cutâneo, ocorre diminuição e desestruturação do colágeno, das fibras elásticas e do ácido hialurônico dérmico".

O envelhecimento cutâneo é um processo natural, que acomete a todos os indivíduos, porém ocorre uma sequência de alterações ao longo à vida, que resultam em perdas de funções do organismo (Bento, 2015; Tramontino, 2009).

Este processo ocorre em decorrência de dois fatores, que são genéticos ou intrínsecos e extrínsecos. O intrínseco é o desgaste natural do organismo juntamente com a influência dos fatores genéticos e o extrínseco é o envelhecimento relacionado ao meio ambiente como poluição, radiação UV, álcool, tabagismo, entre outros (Aguiar et al., 2017; Addor, 2015; Montagner et al., 2009). 


\section{Envelhecimento Extrínseco}

O envelhecimento da pele é consequência de uma série de processos intrínsecos e extrínsecos. O envelhecimento intrínseco é inevitável, ocorre naturalmente no corpo em todas as pessoas e influencia também na evolução do envelhecimento extrínseco, que é induzido por fatores exógenos (Alves; Esteves; Trelles, 2013).

O envelhecimento não deve ser baseado apenas no fator cronológico, porque devem ser considerados os fatores físicos, psicológicos e saúde do indivíduo (Fechine; Trompieri, 2012). O envelhecimento extrínseco é provocado por fatores ambientais, os quais afetam diretamente a pele provocando assim o envelhecimento precoce. Dentre estes fatores extrínsecos podemos citar os mais importantes que são o tabagismo, a radiação UV, poluição, má alimentação, álcool e radicais livres.

O envelhecimento extrínseco é o mais agressivo, neste caso a pele se apresenta clinicamente como manchada, com linhas de expressão profundas, amarelada, frouxa, áspera, dura e a depender pode até causar câncer de pele. Aos 40 anos ocorre o aparecimento de modificações visíveis e palpáveis na pele, as quais se dão devido à diminuição de estrógeno e redução das fibras de colágeno (Carvalho et al., 2016).

O envelhecimento masculino e feminino possui muitas características em comum, mas temos uma maior atenção ao que diferencia estes gêneros. No rosto masculino a presença de pelos faciais, aumento da vascularização facial, aumento da espessura, aumento do conteúdo sebáceo e influências hormonais, influenciam no retardamento do envelhecimento facial. Enquanto as mulheres tendem a ter o aparecimento de rugas mais profundas na região perioral do que os homens. Mulheres que aparentam ser jovens para a idade geralmente se protegem contra exposição solar e possuem a influência de fatores genéticos (Sveikata; Balciuniene; Tutkuviene, 2011).

Dentre os fatores extrínsecos que mais agridem a pele favorecendo o envelhecimento cutâneo, podemos citar tabagismo, radiação UV, poluição, má alimentação, álcool e radicais livres.

\section{- Tabagismo}

O tabagismo está entre os fatores extrínsecos que causam envelhecimento precoce. Ele promove vasoconstricção, o que provoca a diminuição do fluxo sanguíneo e dificulta a oxigenação nos tecidos (Teixeira et al., 2018).

Pode provocar isquemia, diminuição do colágeno e vitamina A, além de aumentar consideravelmente as rugas faciais. É possível observar alguns sinais visíveis em todos os fumantes que são eles: rugas proeminentes, proeminência dos contornos ósseos, pele atrófica e cinzenta, pele pletórica (Carvalho et al., 2016).

A nicotina causa a diminuição do estrógeno na mulher, deixando-as assim muito mais propensas ao envelhecimento precoce do que os homens. O fibroblasto ao ser exposto ao tabaco diminui a síntese de colágeno tipo I e III, essa diminuição leva a perda da elasticidade da pele e a deixa suscetível ao aparecimento de rugas profundas. As mulheres brancas têm uma maior incidência ao aparecimento de aspectos clínicos que são pele seca, atrófica e rugas profundas (Carvalho et al., 2016).

\section{- Radiação UV}

O foto envelhecimento é um dos principais fatores de envelhecimento extrínseco e se caracteriza pela exposição aos raios ultravioletas (UV). Podem ter influência ainda os fatores étnicos e fototipo da pessoa, o qual é definido geneticamente pela quantidade de melanina e definido também pela coloração de acordo com a exposição solar. Dessa forma a pele mais clara acaba sendo mais fotoenvelhecida, já que a melanina tem a função de proteger a pele (Teixeira et al., 2018).

Os raios UV são classificados em A, B e C de acordo com o comprimento de onda. Os raios UVA são importantes para sintetizar vitamina $\mathrm{D}$, porém em excesso se torna prejudicial à pele, porque atinge os fibroblastos causando alterações na elasticidade da pele; o UVB é o mais prejudicial, podendo causar queimaduras e até mesmo câncer de pele; o UVC não atinge a superfície terrestre (Carvalho et al., 2016). 
A radiação UV é responsável por $80 \%$ do envelhecimento facial. A ação da radiação UV é agravada na pele quando combinada com infravermelho, causando assim o envelhecimento precoce (Tassinary; Sinigaglia; Sinigaglia, 2019).

\section{- Poluição}

A poluição atmosférica causa danos de lipídios, proteínas e DNA. E vem sendo um fator determinante na vida de todas as pessoas, já que por conta dos compostos liberados por veículos e fábricas a camada de ozônio vem se degradando e com isso sendo possível uma maior incidência de radiação solar (Ruivo, 2014).

Como a pele está em constante contato com o meio externo ela acaba sofrendo com a ação da poluição, o que leva a diminuição dos antioxidantes (como a vitamina C e E), além de conduzir o aumento das metaloproteinases (Ruivo, 2014).

O contato da pele com a poluição aumenta a produção de radicais livres e consequentemente aumenta os efeitos dos raios ultravioletas. As partículas do meio ambiente danificam a pele e ocorre assim o aumento da produção dos radicais livres que levam ao estresse oxidativo. Esta exposição acaba apresentando sinais como mudanças na pigmentação (Alves; Esteves; Trelles, 2013).

\section{- Má alimentação}

A alimentação é uma das principais fontes de envelhecimento precoce sendo que alguns fatores como composição em nutrientes, temperatura e preparo, influenciam se é um alimento saudável para consumo. Já alimentos saudáveis que, por exemplo são ricos em vitaminas A, C e E, tem efeito antioxidante e antiglicação, o que ajudam a retardar o envelhecimento cutâneo (Lima, 2018).

A relação do envelhecimento com a má alimentação também está ligada com a glicação, que é uma reação não enzimática entre a glicose e as proteínas. O excesso de carboidrato na alimentação induz a glicação (Lima, 2018).

Pode-se observar que houve uma grande mudança dos hábitos alimentares da população, devido ao ritmo de vida acelerado, as pessoas vem escolhendo alimentos de preparo rápido e fácil, como os fast food e alimentos industrializados. Esses alimentos são ricos em gordura e carboidrato, além de conter corantes e pobres em vitaminas e minerais (Lima, 2018).

Pesquisas realizadas nos últimos anos mostraram que ao reduzir a ingestão de calorias diminuiu o dano oxidativo ao DNA mitocondrial e consequentemente desacelerando o metabolismo. À medida que envelhecemos ocorre a diminuição da capacidade funcional e uma restrição calórica retarda a circunstância, mas quando a pessoa está obesa e com alta ingestão calórica aumenta a produção de radicais livres e acelera o envelhecimento (Alves; Esteves; Trelles, 2013).

\section{- Álcool}

O alcoolismo é um dos principais problemas de saúde pública e um dos fatores que reduzem a expectativa de vida. Acelera o envelhecimento assim como o cigarro, já que diminui a quantidade de antioxidantes e consequentemente diminui também a defesa do organismo contra os radicais livres. Além de ser prejudicial à oxigenação e nutrição celular (Barbon; Wietholter; Flores, 2016).

O consumo de álcool interfere na nutrição adequada, já que disputa com os nutrientes desde a ingestão até a absorção. Quanto maior a ingestão de álcool, menor será a qualidade nutricional do indivíduo no organismo e na alimentação (Senger et al., 2011). 


\section{- Radicais Livres}

Os radicais livres (RL) são moléculas instáveis e reativas que causam danos às células do corpo e acelera o envelhecimento. Houve um aumento devido à diminuição nas defesas antioxidantes, que causa danos macromoleculares e perdas funcionais fisiológicas (Teixeira et al., 2018).

Existem os radicais livres endógenos e exógenos, os exógenos são radiação UV, poluição, tabaco, estresse, medicamentos, ou seja, tudo que afeta externamente. Uma das principais fontes exógenas de RL é o foto envelhecimento, que afeta o DNA e causa danos genéticos. Porém, quando produzido em equilíbrio é importante para a defesa do organismo contra agentes estranhos e ajudam os neutrófilos e macrófagos, já que se apresenta como bactericida pela degradação oxidativa dos lipídeos, proteínas e DNA microbianos (Teston; Nardino; Pivato, 2010).

\section{Considerações Finais}

Ao analisar os tópicos abordados é possível verificar quanto os fatores extrínsecos influenciam o envelhecimento precoce e que para a diminuição dessa influência as pessoas devem optar por uma vida mais saudável, visto que o tabagismo, a má alimentação e o álcool são fatores importantes e controláveis para o envelhecimento. Ademais, em relação à radiação UV constata-se que essa poderá ser controlada, mas não evitada, já que a utilização do protetor solar irá ajudar a retardar esse processo. Já quanto a poluição e os radicais livres, seriam necessárias maiores intervenções já que a poluição não depende apenas de uma pessoa, mas sim da população como um todo e os radicais livres são vários fatores que influenciam inclusive um deles sendo a própria poluição.

Ademais, sugere-se a realização de novos estudos para avaliação dos impactos dos fatores extrínsecos no envelhecimento precoce, a fim de trazer mais evidencias aos resultados encontrados e, consequentemente, subsidiar a atuação dos profissionais de saúde no contexto da educação em saúde enquanto estratégia preventiva do cuidado.

\section{Referências}

Addor, F. A. S. (2015). Influence of a nutitional suplemente containing collagem peptides on the properties of the dermis. Surgical \& Cosmetic Dermatology, 7 (2), 116-121. http://dx.doi.org/10.5935/scd1984-8773.201572636

Aguiar, R. V. S. C., Oliveira, C., Barelli, N., Melo, B., Gonçalves, T., \& Feitosa, G. P. V. (2017). Fotoenvelhecimento nos diferentes grupos étnicos. Revista de Iniciação Cientifica, Saúde e Bem-estar, 6(5), 19-30. http://www1.sp.senac.br/hotsites/blogs/revistainiciacao/wp-content/uploads/2017/04/198_IC_ Artigo_Final.pdf

Alves, R., Esteves, T. C., \& Trelles, M. A. (2013). Fatores intrínsecos e extrínsecos envolvidos no envelhecimento da pele. Cir. plást. Iberolatinoam, 39 (1), 89-102. https://scielo.isciii.es/pdf/cpil/v39n1/pt_original13.pdf

Barbon, F. J., Wietholter, P., \& Flores, R. A. (2016). Alterações celulares no envelhecimento humano. J Oral Invest, 5 (1), 61-65. https://seer.imed.edu.br/index.php/JOI/article/view/1379/pdf

Bento, B. S. (2015). Fotoenvelhecimento cutâneo: processo/produtos. Dissertação (Mestrado) - Instituto Superior de Ciências da Saúde Egas Moniz. https://comum.rcaap.pt/bitstream/10400.26/10981/1/Bento\%2c\%20Bruna\%20Silva.pdf

Carvalho, A., Borda, C. C., Moreira, D. M., Pereira, M. A. R., Mário, R. F., \& Zychar, B. C. (2016). Envelhecimento cutâneo induzido pelo tabagismo. Ata de ciências da saúde. http://conic-semesp.org.br/anais/files/2015/trabalho-1000019479.pdf

Fagnan, S., Lima, A. T., Ednigton, L., Fernandes, P., Dantas, M., Benevides, N. A., Nascimento, G. D., Gonçalves, H. C. M., Machado, J. R., Flores, M. L. B., \& Silva, T. S. (2014). Envelhecimento cutâneo. Revista de trabalhos acadêmicos- Campus Niterói, 7. http://www.revista.universo.edu.br/index.php?journal=1reta2\&page=article\&op=view\&path\%5B\%5D=1464\&path\%5B $\% 5 \mathrm{D}=1053$

Fechine, B. R. A., \& Trompieri, N. (2012). O processo de envelhecimento: as principais alterações que acontecem com o idoso com o passar dos anos. Revista científica internacional, 20 (1), 106-132. http://www.interscienceplace.org/isp/index.php/isp/article/view/196/194

Gil, A. C. Como elaborar projetos de pesquisa. (6a ed.), Atlas, 2017.

Lima, F. P. P. (2018). Envelhecimento cutâneo da pele: relação entre o excesso de carboidratos e a Reação de Maillard na formação de produtos de glicação avançada (AGES). Scire Salutis, 8 (1), 1-7. http://www.sustenere.co/index.php/sciresalutis/article/view/CBPC2236-9600.2018.001.0001/1081

Macena, W. G., Hermano, L. O., \& Costa, T. C. (2018). Alterações fisiológicas decorrentes do envelhecimento. Revista Mosaicum, 15 (27), 223-238. https://revistamosaicum.org/index.php/mosaicum/article/view/64/46 
Research, Society and Development, v. 10, n. 6, e21210615761, 2021

(CC BY 4.0) | ISSN 2525-3409 | DOI: http://dx.doi.org/10.33448/rsd-v10i6.15761

Mendes, J. (2020). Envelhecimento(s), qualidade de vida e bem-estar. Psicologia e investigação. In A Psicologia em suas Diversas Áreas de Atuação 3, Ponta Delgada, Portugal, 132-144. https://www.researchgate.net/publication/342365705_Envelhecimentos_qualidade_de_vida_e_bem-estar

Minayo, M. C. S., (2001). Pesquisa Social. Teoria, método e criatividade. (18a ed.).

Montagner, S., \& Costa, A. (2009). Bases Moleculares do fotoenvelhecimento. Anais Brasileiros de Dermatologia, 84 (3), 263-269. https://www.scielo.br/pdf/abd/v84n3/v84n03a08.pdf

Organização Mundial de Saúde (OMS) (2015). Relatório mundial de envelhecimento e saúde. United States of America: Organização Mundial de Saúde. https://apps.who.int/iris/bitstream/handle/10665/186468/WHO_FWC_ALC_15.01_por.pdf\%3Bjse

Ruivo, A. P. (2014). Envelhecimento Cutâneo: fatores influentes, ingredientes ativos e estratégias de veiculação. Universidade Fernando Pessoa. Porto. https://bdigital.ufp.pt/bitstream/10284/4413/1/PPG_21481.pdf

Senger, A. E. V., Ely, L. S., Gandolfi, T., Schneider, R. H., Gomes, I., \& Carli, G. A. (2011). Alcoolismo e tabagismo em idosos: relação com ingestão alimentar e aspectos socioeconômicos. Rev. bras. geriatr. gerontol, 14 (4), 713-719. https://www.scielo.br/pdf/rbgg/v14n4/a10v14n4.pdf

Sveikata, K., Balciuniene, I., \& Tutkuviene, J. (2011). Factors influencing face aging. Literature review. Stomatologija, Baltic Dental and Maxillofacial Journal, 13 (1), 113-6. https://sbdmj.lsmuni.lt/114/114-02.pdf

Tassinary, J., Sinigaglia, M., \& Sinigaglia, G. (2019). Raciocínio clínico aplicado a estética facial. Estética experts.

Teixeira, F. A. B., Carvalho, J. O., Costa, N. S., Brito, N. O. R., Ramos, P. H. R., \& Oliveira, J. M. R. (2018). Avaliação dos fatores extrínsecos e intrínsecos e o processo de aceitação do envelhecimento. III CIPEEX- Ciência para redução das desigualdades, v.2. http://anais.unievangelica.edu.br/index.php/CIPEEX/article/view/2872/1379

Teston, A. P., Nardino, D., \& Pivato, L. (2010). Envelhecimento cutâneo: teoria dos radicais livres e tratamentos visando a prevenção e o rejuvenescimento. Revista Uningá, 1 (1), 71-84. http://revista.uninga.br/index.php/uningareviews/article/view/451/110

Tramontino, V. S., Nuñez, J. M. C., Takahashi, J. M. F. K., Santos-Daroz, C. B., \& Rizzatti-Barbosa, C. M. (2017). Nutrição para idosos. Revista de Odontologia da Universidade de São Paulo, 21 (3), 258-267. http://publicacoes.unicid.edu.br/index.php/revistadaodontologia/article/view/465/359 